\title{
Social media and breastfeeding: an Instagram study
}

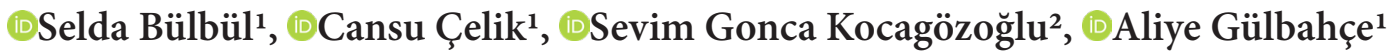 \\ ${ }^{1}$ Kırıkkale University, Faculty of Medicine, Department of Social Pediatrics, Kırıkkale, Turkey \\ ${ }^{2}$ Kahramankazan Hamdi Eriş State Hospital, Clinic of Pediatrics, Ankara, Turkey
}

Cite this article as: Bülbül S, Çelik C, Kocagözoğlu SG, Gülbahçe A. Social media and breastfeeding: an Instagram study. Anatolian Curr Med J 2021; 3(4); 269-273.

\begin{abstract}
Background: Human milk has many proven benefits but breastfeeding rates are far below the desired optimal level. Social media plays an important role in accessing information and advice on health-related issues. There are several studies investigating how the social media has an impact on the community about health-related issues and decisions. We aimed to reveal how much Instagram has touched on breastfeeding and related contents about infant feeding.

Material and Method: This is a descriptive cross-sectional study. We surveyed on Turkish Instagram accounts which only share about children health and diseases between June 2018 and January 2019. We searched the hashtags about child health and infant feeding and we enrolled the accounts that have more than 1000 followers. The obtained data were analyzed by SPSS 16.0 for Windows. The significancy level was accepted as $\mathrm{p}<0.05$.

Results: We enrolled 75 Turkish Instagram accounts. The mean number of posts was 743.77 (22-11349) and the mean number of posts of human milk and formula/bottle feeding were 9.80 and 2.07 ( $\mathrm{p}=0.006$ ). Human milk-related posts received a mean of 1368.3 likes, while those associated with formula/bottle feeding received $437.3(\mathrm{p}=0.007)$.

Conclusion: As a result, it is seen that posts on human milk and breastfeeding were significantly more than those on formula and bottle feeding in social media. The expanding world of the internet today, led us to think that social media can be used as an important tool to increase breastfeeding rates. This should be obviously taken into consideration in future plans of policy makers.
\end{abstract}

Keywords: Bottle feeding, breastfeeding, formula, human milk, social media

\section{INTRODUCTION}

Human milk has many proven benefits for mothers, infants and society with reduced infant mortality rates, protection against infections, and prevention of chronic diseases both in mothers and children. Although these benefits are well known, breastfeeding rates are far below the desired optimal level (1). Facing attitudes that avoid breastfeeding in the community, inadequate support from the partner and close environment, restrictive working conditions, aggressive advertisement campaigns of formula companies can be listed as some of the effecting factors (2).

People who were born between 1980s and early 1990s are known as "Generation Y" or the Internet generation as tending to use the internet for everything. Also, they use social media and online forums, as reliable sources of information (3).
New mothers need support at any sites where she feels insufficient. Social media plays an important role, particularly during the stressful postpartum transition period, in communicating with other people who have similar problems, dealing with stress of being a parent, and accessing information and advice on nutrition, healthcare and nurturing their children (3-6).

Google and Facebook are the most popular networking platforms for providing health related answers and to reduce feelings of social isolation especially in young mothers $(3,7)$. Instagram is another famous social media platform that has more than 700 million active users worldwide and allows sharing photos and videos. "Blogger moms" have become an increasingly widespread phenomenon some of who have thousands of followers (8). 
There are studies investigating how the social media has an impact on the community about health-related issues and decisions. These studies showed positive and negative results on the impact of social media on public health $(9,10)$.

In social media, where false information can spread very quickly, it becomes crucial that the information and advices given by accounts that share about children's health and diseases are medically correct and it has great importance that these accounts focus on essential health issues and topics perceived wrongly by the community (11). The good thing is that, especially when seeking information about breastfeeding issues, women are tending to prefer accessing mostly academic websites or websites that were moderated by health professionals (3).

In this study, we aimed to reveal how much Instagram has touched on human milk, breastfeeding and related contents about infant feeding such as formulas and bottles. Moreover we aimed to see how the followers react to these posts.

\section{MATERIAL AND METHOD}

This descriptive cross-sectional study was conducted between the dates June 2018 and January 2019. This study was conducted by examining social media accounts. Due to the fact that the data is available to the public, neither ethics committee approval nor informed consent were required. All procedures were carried out in accordance with the ethical rules and the principles of the Declaration of Helsinki. Content analysis was done for user info of Turkish Instagram accounts that share posts on child health issues, infant feeding and childhood diseases. We used the hashtags in Turkish such as; \#cocuksagligi (\#childhealth), \#pediatri (\#pediatrics), \#annesütü (\#humanmilk),\#emzirme (\#breastfeeding), \#cocukdoktoru (\#pediatrician), \#cocukbeslenmesi (\#childfeeding), \#mama (\#formula), \#biberon (\#bottle) and scanned similar account suggestions. We didn't obtain an informed consent because the account owners had accepted to share their data in Instagram. We reviewed related posts and searched submissions about human milk, breastfeeding, bottle and formula and we planned to enroll accounts with more than 1000 followers. We examined the account owners' characteristics as gender, occupation, marital status and having children by using descriptive statistical methods. Among the submissions, the posts about human milk with breastfeeding and bottle feeding with formula were divided into two separate categories. The number of received likes and the rates of participation in the accounts were used for statistical analyses. The obtained data were analyzed by SPSS 16.0 for Windows. For statistical analyses, descriptive statistical methods were used and the results were given as numbers, percentages, and mean values. For comparison of means we conducted one-sample t-test. The significancy level was accepted as $\mathrm{p}<0.05$.

\section{RESULTS}

During the study period, 56,189 posts were evaluated and 75 Turkish Instagram accounts with more than 1000 followers who had posts on child health and infant feeding were included in the study. The number of posts related to hashtags about child health and infant feeding between the study period was given in Table 1. Of the accounts' owners $14.7 \%(n=11)$ were male and $82.7 \%(n=62)$ were female; $85.3 \%(n=64)$ were married; $\% 80(n=60)$ had at least one child. Among the whole group $54.7 \%(n=41)$ were working in the health sector, $9 \%(n=7)$ were housewives and $36.3 \%$ $(\mathrm{n}=27)$ were from other professions (Table 2$)$.

\begin{tabular}{|c|c|}
\hline Name of hashtag & Number of shared posts \\
\hline \#annesütü (\#humanmilk) & 127,000 \\
\hline \#emzirme (\#breastfeeding) & 180,000 \\
\hline \#çocuksağlığı (\#childhealth) & 127,000 \\
\hline \#pediatri (\#pediatrics) & 123,000 \\
\hline \#çocukdoktoru (\#pediatrician) & 74,600 \\
\hline \#çocukbeslenmesi (\#childfeeding) & 70,700 \\
\hline \# biberon (\#bottlefeeding) & 55,200 \\
\hline \#mama (\#formula) & 62,000 \\
\hline
\end{tabular}

\section{Table 2. Demographic characteristics of the account owners}

\begin{tabular}{|lcc|}
\hline & N & $\%^{*}$ \\
\hline Gender & & \\
Female & 62 & 82.7 \\
Male & 11 & 14.7 \\
Corporate & 2 & 2.6 \\
Marital status & & \\
$\quad$ Married & 64 & 85.2 \\
Single & 2 & 2.7 \\
Unknown & 9 & 12 \\
Parental status & & \\
$\quad$ Parent & 60 & 80 \\
Not a parent & 13 & 17.3 \\
Corporate account & 2 & 2.7 \\
Occupation & & \\
$\quad$ Healthcare worker & 41 & 54.7 \\
Others & 27 & 36.3 \\
$\quad$ Not working/housewife & 7 & 9 \\
TOTAL & $\mathbf{1 0 0}$ & $\mathbf{1 0 0}$ \\
\hline${ }^{*}$ column percentage is given & & \\
\hline
\end{tabular}

The mean number of posts on the analyzed pages were 743.77 ( $\min 22-\max 11,349$ ). The mean number of posts related to human milk/breastfeeding and baby bottle were $9.80(0-89)$ and $2.07(0-9)$, respectively $(p=0.006)$. The ratio of human milk related and formula related posts to all posts were as 2.57 and 0.75 respectively. Human milk related posts received a mean of 1368 (min 0- $\max$ 25,370 ) likes, while those associated with formula/bottle feeding received $437.3(0-30660)$ likes with a statistically significant difference $(\mathrm{p}=0.007)$ (Table 3$)$. 
When only female page owners were taken into account, the mean number of posts was 783.18 (min 22- $\max$ $11,349)$, and the mean number of posts related to human milk and bottle feeding were 10.68 ( $\min 0$ - $\max 89$ ) and 2.35 ( $\min 0-\max 9$ ) respectively. The ratio of posts related to human milk to all posts was 2.52 , while those associated with formula to all posts was 0.87 . The mean of like numbers of human milk and of formula feeding/ bottle feeding posts were 14,662 ( $\min 13$ - $\max 25,370$ ), and 448 ( $\min 0-\max 3066$ ) respectively (Table 3 ).

\section{DISCUSSION}

Social media is an available communication tool for health-related questions, exchanging ideas with other people who have the same problems or gaining information on specific health problems (12). Social media networks are excellent tools for spreading messages to public, while the cost to deliver information to a large number of people in a very short time and reach young adults is quite low $(13,14)$. With increasing number of followers day by day, which reached up to a maximum of 979,000 of the Turkish Instagram pages 75 were analysed in this study. This huge number of Instagram users only in Turkey can support the above idea.

As compatible with our results $(82.7 \%$ of the account owners in the study were women), recent social media utilization data indicate that the majority of adults who use social media are women and over $80 \%$ are in the 18 40 years age group $(11,12)$. It is not possible to obtain the age information from the social media accounts, so we used the data given by the statistics page of Instagram on January 2018. These data showed that $31 \%$ of the page owners were in 18-24 years age group and 30\% were in 24-35 years age group (15). According to 2017 Turkey Statistical Institute data it was determined that the average age of first-time being a mother was 28.7 years (16). When these data were evaluated together, it can be said that social media could be accepted as the modernday information and communication platform for young people and women in reproductive age.
It has been shown that, the most searched topics on child health issues by the parents were; sleep problems, mental health issues, car safety and childhood vaccines (11). Infant feeding seems to be a less researched topic by parents on social media. Griauzde et al. (7) also showed that mothers were not using social media or other internet sources for gaining information on infant feeding. Our results also reveal that posts on infant feeding (breast feeding/bottle feeding) are relatively low [mean number of posts on the analysed pages was (743.77), mean number of posts related to human milk/breastfeeding was 9.80 and bottle feeding/formula was 2.07]. For this reason, Turkish Ministry of Health should encourage healthcare professionals to use social media more actively and share correct baby feeding recommendations.

Due to the interactive and unifying structure of social media, breastfeeding could be a health activity that can be easily campaigned via these networks. Common problems, encountered difficulties, fears about breastfeeding can be discussed and resolved and breastfeeding can be strongly encouraged on these platforms by the comments, sharing of stories and information posted under these issues (1719). In previous studies, it has been shown that campaigns conducted via the Internet significantly increased the level of knowledge, positive beliefs, and desire of breastfeeding compared to information provided by "offline" healthcare professionals $(20,21)$. In our study breast milk related posts received more mean of likes than formula/bottle feeding with a statistically significant difference. Considering as a preliminary study, our study results might give a positive impression that social media can have a positive effect on breastfeeding rates. Taking into account the ages of those who frequently use social media, strategic campaigns for adolescent girls and boys would be an innovative approach to promote and support breastfeeding in the next generation (22).

In recent years, use of internet has increased among the young pregnant women and mothers for getting information on baby care (23). However, this increase also poses a risk for the spread of false information. Even though the fact that social media is not open to control in terms of information accuracy, it is obvious

\begin{tabular}{|c|c|c|c|c|}
\hline & $\begin{array}{c}\text { Female } \\
\text { mean (min-max) }\end{array}$ & $\begin{array}{c}\text { Male } \\
\text { mean (min-max) }\end{array}$ & $\begin{array}{c}\text { Healthcare W } \\
\text { mean (min-max) }\end{array}$ & $\begin{array}{c}\text { Total } \\
\text { mean (min-max) }\end{array}$ \\
\hline Number of human milk posts & $10.68(0-89)$ & $5.62(0-28)$ & $13.76(0-89)$ & $9.8(0-89)$ \\
\hline Number of baby bottle posts ${ }^{1}$ & $2.35(0-9)$ & $0.69(0-2)$ & $1.49(0-8)$ & $2.07(0-9)$ \\
\hline Number of formula posts ${ }^{1}$ & $1.92(0-8)$ & $0.46(0-2)$ & $1.54(0.7)$ & $1.67(0-8)$ \\
\hline Likes of human milk posts ${ }^{2}$ & $14,662(13-25,370)$ & $9375(0-8793)$ & $630(13-5259)$ & $1368.3(0-25,370)$ \\
\hline Human milk posts/Total posts & 2.52 & 2.82 & 3.36 & 2.57 \\
\hline Formula posts/total posts & 0.87 & 0.19 & 0.67 & 0.75 \\
\hline
\end{tabular}


that healthcare professionals provide social and medical support to these mothers with accurate information on their platforms (24). Our study group (determined accounts) was also mostly composed of healthcare professionals (54.7\%). Therefore, it seems that, though, healthcare professionals are already using these platforms and this number is increasing day by day, it is still not enough.

There are relatively few studies on the visibility and communication of nursing mothers and healthcare professionals on social media and how this communication can be effectively used to support breastfeeding. In this sense, our study is important as it is one of the first studies in terms of the visibility of breastfeeding and breastmilk on social media. Moreover, it can provide valuable preliminary information to establish a systematic network of "online" breastfeeding support and information.

\section{Limitation}

This study has some limitations. The ages of the account holders and their purpose of the social media usage couldn't be reached. We could only define the occupations and genders of them. The undefined characteristics of the account holders could be an important part of the information. We believe that, valuable information can be gained by organizing a study focusing on the detailed demographic characteristics and expectations of people using social media to share information on child health and infant feeding.

\section{CONCLUSION}

In conclusion, it seems that posts on breast milk and breastfeeding were significantly more than those about formula in social media. However, it is still not at the desirable levels. At present, social media could be accepted an important and easily available platform for physicians to serve accurate and scientific information to large number of people.

\section{ETHICAL DECLARATIONS}

Ethics Committee Approval: This study was conducted by examining social media accounts. Due to the fact that the data is available to the public, neither ethics committee approval nor informed consent were required.

Referee Evaluation Process: Externally peer-reviewed.

Conflict of Interest Statement: The authors have no conflicts of interest to declare.

Financial Disclosure: The authors declared that this study has received no financial support.
Author Contributions: All of the authors declare that they have all participated in the design, execution, and analysis of the paper, and that they have approved the final version.

\section{REFERENCES}

1. Victora CG, Bahl R, Barros AJD, et al. Breastfeeding in the $21^{\text {st }}$ century: epidemiology, mechanisms, and lifelong effect. Lancet 2016; 387: 475-90.

2. Sriraman K, Kellams A. Breastfeeding: What are the barriers? why women struggle to achieve their goals. J Women's Health 2016; 25: 714-22.

3. Alianmoghaddam N, Phibbs S, Benn C. "I did a lot of Googling": A qualitative study of exclusive breastfeeding support through social media. Women Birth 2019; 32: 147-56.

4. Umberson D, Pudrovska T, Reczek C. Parenthood, childlessness, and well-being: a life course perspective. J Marriage Fam 2010; 72: 612-29.

5. Bartholomew MK, Schoppe-Sullivan SJ, Glassman M, Kamp Dush CM, Sullivan JM. New parents' Facebook use at the transition to parenthood. Fam Relat 2012; 61: 455-69.

6. Doty JL, Dworkin J. Online social support for parents: a critical review. Marriage Fam Rev 2014; 50: 174-98.

7. Griauzde DH, Kieffer EC, Domoff SE, et al. The influence of social media on child feeding practices and beliefs among Hispanic mothers: A mixed methods study. Eat Behav 2020; 36: 101361.

8. Number of monthly active Instagram users from January 2013 to September 2017 (in millions). Statista.com (Access March 2019)

9. Asiodu IV, Waters CM, Dailey DE, Lee KA, Lyndon A. Breastfeeding and social media among first-time African American mothers. J Obstet Gynecol Neonatal nurs 2015; 44: 268-78.

10. Tomfohrde O, Reinke J. Breastfeeding mothers' use of technology while breastfeeding. Comput Hum Behav 2016; 64: 556-61.

11. Bryan MA, Evans Y, Morishita C, Midamba N, Moreno M. Parental perceptions of the internet and social media as a source of pediatric health information. Acad Pediatr 2020; 20: 31-8.

12. Shieh C, Khan I, Umoren R. Engagement design in studies on pregnancy and infant health using social media: Systematic review. Prev Med Rep 2020; 19: 101113.

13. Strecher V. Internet methods for delivering behavioral and health-related interventions (eHealth). Ann Rev Clin Psychol 2007; 3: 53-7.

14. Vance K, Howe W, Dellavalle R P. Social internet sites as a soure of public health information. Dermatol Clin 2009; 27: 133-6.

15. Distribution of Instagram users worldwide as of January 2018, by age group website: https: //www.statista.com/statistics/325587/ instagram-global-age-group/ (Access december 2018)

16. Türkiye Nüfus ve Vatandaşlik İşleri Müdürlüğü, TÜİK, Doğum istatistikleri, 2018 (Turkey Directorate of Population and Citizenship Affairs, TSI, Birth Statistics, Access : December 2018)

17. Dornan B A, Oermann MH. Evaluation of breastfeeding web sites for patient education. Am J Matern Child Nurs 2006; 31: 18-23.

18. Riordan J. Teaching breastfeeding on the web. J Hum Lact 2000; 16: 231-4.

19. Thomas J, Shaikh U. Electronic communication with patients for breastfeeding support. J Hum Lact 2007; 23: 275-9.

20. O'Connor ME, Brown EW, Lewin LO. An Internet-based educational program improves breastfeeding knowledge of maternal-child healthcare providers. Breastfeed Med 2011; 6: 421-7. 
21. Pate B. A systematic review of the effectiveness of breastfeeding intervention delivery methods. J Obstet Gynecol Neonatal Nurs 2009; 38: 642-3.

22. Harding K, Aryeetey R, Carroll G, Lasisi O, Pérez-Escamilla R, Young M. Breastfeed4Ghana: Design and evaluation of an innovative social media campaign. Matern Child Nutr 2020; 16: e12909.

23. Shaikh U, Scott B J. Extent, accuracy and credibility of breastfeeding information on the internet. J Hum Lact 2005; 21 : $175-83$.

24. Bautista JR, Zhang Y, Gwizdka J. Healthcare professionals' acts of correcting health misinformation on social media. J Med Inform 2021; 148: 104375 . 